\title{
A preliminary feasibility study to evaluate the safety, acceptability and efficacy of PPIUCD prior to implementation of PPIUCD service
}

\author{
M.V. Ramana Rao ${ }^{1}$, Naima Fathima ${ }^{2, *}$, Swathi. ${ }^{3}$ \\ ${ }^{1}$ Associate Professor, ${ }^{2}$ Professor, ${ }^{3}$ Junior Resident, Dept. of Obstetrics and Gynaecology, SVS Medical College, Mahabubnagar, \\ Telangana, India
}

*Corresponding Author: Naima Fathima

Email: naimaatmbnr@gmail.com

Received: $30^{\text {th }}$ September, 2018

Accepted: $29^{\text {th }}$ October, 2018

\begin{abstract}
Introduction: PPIUCD is a very safe, reversible, long term contraceptive. The recommended interval between pregnancies is at least 24 months in order to reduce the risk of adverse maternal, perinatal and infant outcomes. In our district the usage of PPIUCD is $0.1 \%$ and $60 \%$ of deliveries take place in private health facilities. This preliminary study is conducted in a private teaching hospital with the aim to determine proportion of women accepting PPIUCD and to develop our own data regarding immediate complications to guide us in counselling the women and to implement PPIUCD services.

Materials and Methods: This prospective feasibility study was done from July 2017 to January 2018. 100 women attending the for antenatal checkups were counselled for PPIUCD. The women who consented were inserted with PPIUCD.

Results: Acceptance rate was 30\% and most of the women who accepted PPIUCD were primiparae (58.3\%). An analysis of the reasons for acceptance of PPIUCD showed that long term efficacy (33.3\%), safety (20\%), fewer clinic visits (16.6\%) and non hormonal $(13.3 \%)$ were the most common reasons for acceptance.

Conclusion: The PPIUCD is safe having no reported incidence of perforation with low rate of expulsion, pelvic infection and few lost strings and these complications can be reduced further with training and practice. The acceptance and continuation rates can be improved with counselling and strategic follow up protocols in our district with very low rate of PPIUCD usage.
\end{abstract}

Keywords: Postpartum intra uterine contraceptive device, Long acting reversible contraceptives, Acceptance, Complications.

\section{Introduction}

Intra uterine contraceptive device (IUCD) is one of the common method of long acting reversible contraceptives (LARC). Currently globally, $14.3 \%$ of women of reproductive age use IUCD. ${ }^{2}$ Healthy timing and spacing of pregnancies have a positive effect on maternal health and newborn outcome. According to a study the unmet need of family planning in the first year postpartum in India is about $65 \% .^{6}$ Many studies have shown that adverse maternal, perinatal and neonatal outcomes are related to pregnancies spaced too closely together. An encouraging trend is seen in the number of women coming for institutional deliveries. Postpartum period provides an important window of opportunity for women to receive contraceptive service. In India the usage of contraception is $58.3 \%$ and the usage of modern spacing methods is $11.4 \% .^{3}$ The modern IUCD is a highly effective, safe, private, long acting, coitus independent and rapidly reversible method of contraception with few side effects. IUCD is the most cost effective method of contraception.

According to WHO, Medical Eligibility Criteria, an IUCD can be inserted immediately after delivery of the placenta either after vaginal delivery or during Caesarean section, known as postplacental, or upto 48 hours postpartum referred to here as postpartum Intrauterine Contraceptive Device (PPIUCD). ${ }^{7}$ A 2010 Cochrane review concluded that PPIUCD is a safer and effective contraceptive method. ${ }^{5}$ Initiation of contraception during this period is important to prevent unintended pregnancy and short birth intervals. It can avert more than $30 \%$ of maternal deaths and $10 \%$ of child mortality. ${ }^{1}$ The PPIUCD enables the women to leave the hospital with a safe and highly effective, long acting contraceptive. This is particularly important for women who have limited access to health care services. The women do not usually access family planning services in the postpartum period due to various socioeconomic factors even though they desire to space the pregnancies. Hence the immediate postpartum period is potentially an ideal time to begin contraception as women are more strongly motivated to do so at this time, which also has the advantage of being convenient for both women and health care providers. PPIUCD insertion has the added advantage of eliminating six weeks waiting period and an additional hospital visit.

According to the National Family Health Survey -4 conducted in 2015-16, in our district, Mahabubnagar the usage of any contraceptive method by women of reproductive age is $64.3 \%$ and usage of IUD/PPIUCD is $0.1 \% .^{4}$ This prospective feasibility study was undertaken to study the acceptability, safety, feasibility and immediate complications of immediate PPIUCD among parturient women at a private tertiary hospital and to develop our own institutional data to guide us to counsel the women in extending the PPIUCD services. 


\section{Materials and Methods}

This prospective feasibility study was conducted from July 2017 to January 2018. Counselling was given to 100 pregnant women about the PPIUCD during the antenatal period and when the woman is admitted for delivery. A structured questionnaire was administered to all participants and consent was taken from all participants who accepted IUCD. Women who accepted the IUCD were inserted with the device either after vaginal delivery or during Caesarean section or before discharge (within 48 hours). These women were followed up at 6 weeks for complications. The acceptance rate and reasons for acceptance and decline were also recorded. Total number of women counselled were 100 and 30 women accepted PPIUCD. 70 women declined. Two women did not turn up for follow up and could not be traced. 28 women were followed up. Complications were noted in 6 women and 22 women did not have any complications. Data was entered in Excel sheet and proportions were calculated.

\section{Inclusion Criteria}

1. 18-45years of age

2. Women fulfilling WHO Medical Eligibility Criteria.

3. Women who gave informed written consent and had either vaginal delivery or caesarean section.

\section{Exclusion Criteria}

1. Clinical evidence of Chorioamnionitis or history of prolonged premature rupture of membranes $>18$ hours.

2. Known uterine malformations.

3. Evidence of active STIs.

4. Postpartum hemorrhage requiring further management.

5. Manual removal of the placenta.

\section{Results}

Majority of the women who accepted PPIUCD were young, in the age group of 23-27 years (70\%). Women with primary and secondary education has higher acceptance rate than those with no formal education. $63 \%$ of the women with secondary education has accepted PPIUCD. Majority of the women who declined PPIUCD did not have formal education $(48.5 \%)$ or had primary education $(35.7 \%)$. Most of the women who accepted PPIUCD were primipara $(58.3 \%)$ who wanted spacing for 3 or more year. Majority of the women (84\%) had their last childbirth less than 2 years ago. The duration since the last child birth was significantly associated with the acceptance of PPIUCD.

Two thirds of women $66.7 \%$ had postplacental insertion after vaginal delivery and $33.3 \%$ had during Caesarean section. No women had PPIUCD inserted in the immediate postpartum $<48$ hours after delivery.

Out of the total women studied, $43 \%$ had used at least one method of contraception and $57 \%$ had not used any form of contraception at all. Two thirds of women who accepted PPIUCD had used some form of contraception previously. Interval IUCD was one of the least used methods $(2 \%)$. The number of women who had used contraception in the past were statistically significantly associated with acceptance of PPIUCD.

A total of 70 women declined PPIUCD. Among those who declined PPIUCD, majority of them were due to fear of pain and bleeding (31.4\%) followed by refusal by the partner (25.7\%).

An analysis of the reasons for acceptance of PPIUCD showed that long term efficacy $(33.3 \%)$, safety (20\%), fewer clinic visits (16.6\%) and non hormonal $(13.3 \%)$ were the most common reasons for acceptance. Preferences for other forms of contraception among those who declined PPIUCD varied from tubal ligation being the most common method $(38.5 \%)$ and interval IUCD being the least preferred method $(8.5 \%)$. A significant proportion (20\%) of those who declined PPIUCD did not want to use any contraception. Most of the women who chose permanent sterilization were para 2 and more.

Out of the 28 women who were followed up 6 weeks after PPIUCD insertion, 21.4\% developed complications. The commonest complication was expulsion of IUCD (10.7\%). There was no case of uterine perforation.

\section{Discussion}

Family planning is a key intervention in reducing maternal, newborn and child mortality and morbidity through preventing unintended pregnancies and pregnancies with shorter intervals. A study of postpartum women in D\&HS shows that a very high percentage of women, $40 \%$ who intend to use a contraceptive during the first year postpartum were not using contraception. This survey also found that a very small percentage of women $3-8 \%$, want another child within 2 years of last child birth but $35 \%$ have children within 2 years. ${ }^{1}$

PPIUCD is a good choice for postpartum women who want to either space or limit subsequent pregnancies but are unlikely to access Family Planning services due to various reasons.

The acceptance rate in our study is comparable to an international study done in Egypt in 2004 when PPIUCD was still a new concept. ${ }^{8}$ The acceptance rate was $28.9 \%$ when women were counselled during antenatal and immediate postpartum periods. Acceptance rate was the same during antenatal and postpartum counselling. (Mohamed SA et al). It was also demonstrated in this study that if the woman accepted immediate or early insertion of the IUCD while still in the hospital were more likely to have an IUD inserted $(71.2 \%)$ than those who chose interval IUD $(7.1 \%)$. The acceptance rates across different parts of India vary from $8.5 \%$ (Vidyarama et al, Andhra Pradesh), 17\% (Mishra et al, Odisha), 21.7\% (Gautam $\mathrm{R}$ et al, UP), $10.5 \%$ (Alukal AT et al, Kerala). ${ }^{9-12}$ 
$70 \%$ of the women who accepted PPIUCD were in the age group of 23-27 years and the same age group dominated those who declined, $80 \%$ of those who declined were $<27$ years of age. In a large study done in different states the mean age of women accepting PPIUCD was 24 years (Kumar. S et al). ${ }^{13}$ In other studies the average age was noted to be $<30$ years. ${ }^{14,15}$

Understandably the acceptance rate for PPIUCD is higher among primiparous women who would like to avoid another pregnancy soon. In our study $58.3 \%$ of the women were para 1 . In other studies the primiparous women were $15.4 \%$ (Vidyarama et al), 73.1\% (Maluchuru $\mathrm{S}$ et al), 53\% (Kumar. $\mathrm{S}$ et al), $20.7 \%$ (Mishra S et al).

A woman's education is a powerful predictor of both fertility and contraceptive use. A study done in fourteen Sub-Saharan African countries female schooling has a positive relationship with contraceptive use at all levels. secondary schooling is associated with substantially lower fertility in all countries. ${ }^{16}$ In our study majority of the women who accepted PPIUCD had secondary education (63.3\%) and on the contrary majority who declined did not have any formal education $(48.5 \%)$.

In our study we found that PPIUCD insertions following vaginal delivery were more common than following Caesarean section. This finding is contradicting to many other studies done in various parts of India. In Jani P.S. et al intracaesarean insertion was $62.3 \%$, postplacental $30.66 \%$ and postpartum $<48 \mathrm{hrs}$ was $7 \%$. In a large study spanning over 6 years, the insertion rate following Caesarean section and vaginal delivery was almost equal with postpartum <48hrs insertions being a very small proportion, $3.5 \% .^{17}$

An analysis of reasons for acceptance has revealed that long term duration and the safety profile of PPIUCD were the prime reasons which motivated the women in our study. In other studies the reasons for acceptance were diverse such as 'my doctors' advice must be a good one', 'no remembrance once inserted' (Mishra S et al). These factors emphasise the role a physician plays in helping the women in making contraceptive choices. In another study conducted in different health facilities by Kumar $\mathrm{S}$ et al the reasons for acceptance were long acting $(87.6 \%)$, free of charge service $(22 \%)$. In studies done in our neighbouring state showed that long term efficacy (55.2\% Maluchuru S et al), safety (22.9\% Vidyarama et al) and one time procedure $(42.5 \%)$ were reasons behind acceptance.
The PPIUCDs are known to be associated with complications such as expulsion, pain during insertion, infection, lost strings and heavy menstrual bleeding. The signicant complication noted by us was expulsion in $10.7 \%$ of cases. Another study of 1317 women in North India reported a cumulative expulsion rate of $10.7 \%$ by 6 months. ${ }^{18}$ Earlier studies have reported higher expulsion rates which was related to the insertion technique. However over the years the expulsion rates have come down due to the training of the personnel.

In our study we found that fear of pain, heavy bleeding and refusal of the partner contributed as the main reasons $(57.1 \%)$ for refusal of PPIUCD. In a study by Mishra et al the primary reason for refusal was, not enough knowledge about PPIUCD in $66.9 \%$ followed by partner and family refusal $50.2 \%$. Preference for another method was reason for refusal in $46.6 \%$ in a study by Maluchuru $\mathrm{S}$ et al.

The women who declined PPIUCD in our study preferred permanent sterilization in $38.5 \%$ of cases. In many studies a significant proportion of women declined PPIUCD because of non acceptance of partner or family members. This underlines the importance of involving family members and husband in counselling the women for PPIUCD. The role of the social environment in contraceptive decision-making is considerable to such an extent that the other family members influence the decision making in contraceptive choice and the family size in India. Many studies have shown that when the partner is involved in contraceptive counselling and decision making, the acceptance and continuation rates are higher.

The limitation of this study is unbooked women were not included as these women received antenatal care somewhere else. This population also needs to be targeted for PPIUCD as they are likely to accept PPIUCD in the postpartum period.

We conducted this study to develop our own data pertaining to the PPIUCD such as rate of complications, failure, continuation rates to guide us in counselling the women. This data will also forms base line data against which our future performance can be audited. According to the National Family health Survey-4, the institutional birth rate in Mahabubnagar is $78.4 \%$ but institutional births in public facilities account for just $35 \%$ and significantly, $60 \%$ of deliveries take place in private health facilities. This offers a good opportunity for health facilities to offer PPIUCD services and can contribute to increase the usage of PPIUCD in the district.

Table 1: Analysis of demographic variables

\begin{tabular}{|l|c|c|c|c|}
\hline \multirow{2}{*}{ Age in years } & \multicolumn{2}{|c|}{ Accepted } & \multicolumn{2}{c|}{ Declined } \\
\cline { 2 - 5 } & $\mathbf{N = 3 0}$ & \% percentage & $\mathbf{N = 7 0}$ & Percentage \\
\hline $18-22$ & 9 & 30 & 29 & 38 \\
\hline $23-27$ & 21 & 70 & 27 & 48 \\
\hline $28-32$ & 0 & 0 & 11 & 11 \\
\hline
\end{tabular}




\begin{tabular}{|l|c|c|c|c|}
\hline $33-37$ & 0 & 0 & 3 & 3 \\
\hline Education & & & & \\
\hline No formal & 2 & $6.66 \%$ & 34 & $48.5 \%$ \\
\hline Primary & 9 & $30 \%$ & 25 & $35.7 \%$ \\
\hline Secondary & 19 & $63.3 \%$ & 11 & $15.7 \%$ \\
\hline Parity & & & & \\
\hline Para 1 & 21 & $58.3 \%$ & 36 & $51.4 \%$ \\
\hline Para 2 & 7 & $41.1 \%$ & 17 & $24.2 \%$ \\
\hline Para $\geq 3$ & 2 & $11.7 \%$ & 17 & $24.2 \%$ \\
\hline
\end{tabular}

Table 2: Timing of insertion

\begin{tabular}{|l|c|c|}
\hline \multicolumn{1}{|c|}{ Timing of insertion } & Number & \% \\
\hline Postplacental, vaginal & 20 & $66.7 \%$ \\
\hline Intracaesarean & 10 & $33.3 \%$ \\
\hline $\begin{array}{l}\text { Immediate } \\
\text { postpartum<48hrs }\end{array}$ & 0 & 0 \\
\hline
\end{tabular}

Table 3: Analysis of reasons for declining PPIUCD

\begin{tabular}{|l|c|c|}
\hline \multicolumn{1}{|c|}{ Reason } & Number & \% \\
\hline $\begin{array}{l}\text { Fear of pain and heavy } \\
\text { bleeding }\end{array}$ & 22 & 31.4 \\
\hline Partner refusal & 18 & 25.7 \\
\hline Fear of expulsion & 9 & 12.8 \\
\hline $\begin{array}{l}\text { Preference for other } \\
\text { methods }\end{array}$ & 8 & 11.4 \\
\hline Not sure about PPIUCD & 8 & 11.4 \\
\hline No reason & 5 & 7.1 \\
\hline
\end{tabular}

Table 4: Reasons for acceptance

\begin{tabular}{|l|c|c|}
\hline \multicolumn{1}{|c|}{ Reason } & Number & $\mathbf{\%}$ \\
\hline Long term & 10 & 33.3 \\
\hline Safe & 6 & 20 \\
\hline Few clinic visits & 5 & 16.6 \\
\hline Nonhormonal & 4 & 13.3 \\
\hline No remembrance & 2 & 6.6 \\
\hline Reversible & 2 & 6.6 \\
\hline $\begin{array}{l}\text { No interference with } \\
\text { breast feeding }\end{array}$ & 1 & 3.3 \\
\hline
\end{tabular}

Table 5: Preference for other forms of contraception

\begin{tabular}{|l|c|c|}
\hline \multicolumn{1}{|c|}{ Method } & Number & $\mathbf{\%}$ \\
\hline Permanent sterilization & 27 & 38.5 \\
\hline Male condoms & 16 & 22.8 \\
\hline OCP & 7 & 10 \\
\hline Interval IUCD & 6 & 8.5 \\
\hline None & 14 & 20 \\
\hline
\end{tabular}

Table 6: Complications

\begin{tabular}{|l|c|c|}
\hline \multicolumn{1}{|c|}{ Complication } & Number & \% \\
\hline Expulsion & 3 & 10.7 \\
\hline Lost strings & 2 & 7.1 \\
\hline Infection & 1 & 3.5 \\
\hline
\end{tabular}

\section{Conclusion}

PPIUCD is a long term reversible contraceptive which is effective, safe and convenient contraceptive intervention for women following vaginal and ceasarean deliveries. PPIUCD inserted within $10 \mathrm{~min}$ after placental delivery has high retention rate with less complications. Increasing institutional deliveries and high receptivity in postpartum period has made PPIUCD as one of the important methods of contraception in puerperium. The expulsion rate though was not high and can be reduced further with training of the personnel. This data would help us to develop our own protocols to strengthen our family planning services in the district which has $0.1 \%$ usage of PPIUCD. Good counselling about PPIUCD by a trained person preferably in the antepartum period is crucial in helping the woman to make an informed choice. Every clinician/other health care personnel with whom a woman comes in contact during her pregnancy should take part in counselling the woman even if the woman chooses to deliver in another health facility.

\section{References}

1. Postpartum IUCD Reference Manual. New Delhi: Family Planning Division, Ministry of Health and Family Welfare, Government of India;2010.

2. Alkema, L. National, regional and global rates and trends in contraceptive prevalence and unmet need for family planning between 1990 and 2015: a systematic and comprehensive analysis. The Lancet. 2013;381(9878):1642-1652.

3. Aalok Ranjan Chaurasia. Contraceptive Use in India: A Data Mining Approach. International Journal of Population Research, Volume 2014, Article ID 821436, 11 pages http://dx.doi.org/10.1155/2014/821436

4. National Family health Survey, international Institute for Population Sciences, available at http://rchiips.org/NFHS/FCTS/TG/TG_FactSheet_538_M ahbubnagar.pdf

5. Grimes DA, Lopez LM, Schulz KF, Stuart G, Van Vliet HA. Immediate post-partum insertion of intrauterine devices. Cochrane Database Syst Rev. 2015;(6). doi: 10.1002/14651858.CD003036.pub3.

6. Borda M. Family Planning Needs during the Extended Postpartum Period in India. Access Family Planning Initiative Brief, 2009. Available at http://www.accesstohealth.org/toolres/pdfs/India_Analysi s.pdf, on March 14, 2013.

7. World Health Organization: Medical eligibility criteria for contraceptive use. In: WHO, eds. WHO Book. 4th ed. Geneva: World Health Organization; 2010.

8. Mohamed SA, Kamel MA, Shaaban OM, Salem HT. Acceptability for the use of postpartum intrauterine contraceptive devices: Assiut experience. Med Princ Pract. 2003;12(3):170-5. 
9. R. Vidya Rama, T. Nagamani, Prasad Usha. PPIUCD as a Long Acting Reversible Contraceptive (LARC)-An experience at a tertiary care center. International Journal of Scientific Research. 2015;4(5).

10. Mishra S. Evaluation of Safety, Efficacy, and Expulsion of Post-Placental and Intra-Cesarean Insertion of Intrauterine Contraceptive Devices (PPIUCD). J Obstet Gynaecol India. 2014;64(5):337-43. doi: 10.1007/s13224-014-0550-3. Epub 2014 May 18.

11. Rajni Gautam, K. N. Arya, S. Kharakwal, Sudhir Singh, Monika Trivedi. overview of Immediate PPIUCD application in Bundelkhand Region. Journal of Evolution of Medical and Dental Sciences. 2014;3(36):9518-9526.

12. Alukal AT, Raveendran RC, George L. PPIUCD: awareness and reasons for non-acceptance. Int J Reprod Contracept Obstet Gynecol. 2018;7:582-6.

13. Kumar S, Sethi R, Balasubramaniam S. Women's experience with postpartum intrauterine contraceptive device use in India. Reproductive Health. 2014;11:32. doi:10.1186/1742-4755-11-32.

14. Jani PS. Prospective study on outcomes of postpartum intrauterine contraceptive device including safety, efficacy and expulsion at GMERS Medical College, Dharpur-Patan, Gujarat, India. Int J Reprod Contracept Obstet Gynecol. 2018;7:3131-5.

15. Maluchuru S, Aruna V, Prabhavathi N. Post-partum intrauterine device insertion: 2 years' experience at tertiary care center in Guntur medical college/govt general hospital, Guntur. J Dental Med Sci. 2015;14(3):56-61.
16. Martha Ainsworth, Kathleen Beegle, Andrew Nyamete. The Impact of Women's Schooling on Fertility and Contraceptive Use: A Study of Fourteen Sub-Saharan African Countries. The World Bank Economic Review, 1996;10(1):85-122.

17. Mahadevan G, Chandika NB. Evaluation of safety, efficacy, acceptance and expulsion of post placental intrauterine contraceptive device in a tertiary care centre. Int J Reprod Contracept Obstet Gynecol. 2018;7:542-5.

18. Shukla M, Qureshi S, Chandrawati. Post-placental intrauterine device insertion - a five year expérience at a tertiary care centre in north India. Indian J Med Res. 2012;136:432-435.

How to cite this article: Rao M.V. R, Fathima N, Swathi J. A preliminary feasibility study to evaluate the safety, acceptability and efficacy of PPIUCD prior to implementation of PPIUCD service. Indian J Obstet Gynecol Res. 2018;5(4):476-480. 